\title{
Epidemiological Assessment of Knowledge and Perceptions towards Corona Virus Disease-19 among Gyadi-Gyadi Communities in Kano, Nigeria
}

\author{
Ahmad Salisu Aliyu ${ }^{1, *}$, Ahmed Habibu Badawi ${ }^{1}$, Hussaini Mohammed ${ }^{2}$, Nuru Yakubu Umar ${ }^{3}$, \\ Samira Shehu ${ }^{4}$ \\ ${ }^{I}$ Medical Laboratory Department Infectious Diseases Hospital (IDH) Kano, Nigeria \\ ${ }^{2}$ College of Nursing Sciences, Abubakar Tafawa Balewa University Teaching Hospital Bauchi, Bauchi State, \\ Nigeria \\ ${ }^{3}$ College of Nursing and Midwifery, Bauchi State, Nigeria \\ ${ }^{4}$ Medical Laboratory Department Mariya Sunusi Maternity Hospital Kano, Nigeria
}

*Corresponding Author: Ahmad Salisu Aliyu, Medical Laboratory Department Infectious Diseases Hospital (IDH) Kano, Nigeria. Email: salisuahmadaliyu@yahoo.com

\begin{abstract}
Background: Worldwide coronavirus disease 2019 (COVID-19) is a major public health problem. Coronavirus $(\mathrm{CoV})$ is a zoonotic pathogen that can be transmitted via animal-to-human and human-to-human interactions. It was found to be originated from Wuhan, Hubei, China, in December 2019, and was recognized as a pandemic by the World Health Organization, spreading to more than 190 countries and territories, resulting near 74,816 deaths and 1,349,660 affected cases as on 7 April 2020. Poor knowledge and perceptions towards COVID-19 contributed to the prolonged transmission of diseases in the community. The aim of this study was to assess knowledge and perceptions towards COVID-19 among Gyadi-Gyadi communities in Kano, Nigeria.
\end{abstract}

Methodology: A community based cross-sectional study was conducted in Gyadi-Gyadi from April, 2020 to May, 2020. Data was collected using a pretested structured questionnaire. Descriptive analysis was performed to obtain the frequency distribution of the variables.

Results: The result shows that 300 participants responded to the questionnaire. 165(55\%) respondents were male and the remaining 135 (45\%) were female. Regarding sign and symptom $162(54 \%)$ of the respondents have answered headache, fever, cough, sore throat, and flu are symptoms of COVID-19.Concerning perceptions, 145 (48.3\%) perceived that lack of hand washing practice contribute to COVID-19.

Conclusion: The study revealed that the respondents have low knowledge towards COVID-19. However, the perception status of the respondents towards COVID-19 was poor. Supportive supervision for health extension workers in order to strengthen effective health education to the community on the causes, sign and symptoms of the diseases and possible preventives measures are urgently needed.

Keywords: COVID-19, Knowledge, Perception, Gyadi-Gyadi, Kano, Nigeria.

\section{INTRODUCTION}

The novel Coronavirus Disease 2019 or COVID 19 is a respiratory illness that can spread from person to person causing flu like symptoms and in severe cases death. It was found to be originated from Wuhan, Hubei, China, in December 2019, and was recognized as a pandemic by the World Health Organization [WHO, 2020, CDC, 2020], spreading to more than 190 countries and territories, resulting near
74,816 deaths and 1,349,660 affected cases as on 7 April 2020. Since there is no vaccine or specific antiviral treatment for COVID-19 there are a number of suggested strategies in the control like social distancing and personal hygiene practices. Even then, the pandemic has led to severe global socioeconomic disruption, [WHO, 2020] and discrimination to foreigners [Zhai and Du, 2020].

Coronavirus $(\mathrm{CoV})$ infections are emerging respiratory viruses that are known to cause 
illness ranging from the common cold to severe acute respiratory syndrome (SARS) [Yin and Wunderink, 2018]. CoV is a zoonotic pathogen that can be transmitted via animal-to-human and human-to-human interactions [ $\mathrm{Li}$ et al, 2020]. Multiple epidemic outbreaks occurred in 2002 (SARS), with approximately 800 deaths, and in 2012 (Middle East respiratory syndrome coronavirus, MERS-CoV), with 860 deaths [Li et al, 2020, Bhagavathula and Shehab, 2020]. About 8 years after the MERS-CoV epidemic, the current outbreak of coronavirus disease 2019 (COVID-19) in Wuhan City, Hubei Province, China, has emerged as a global outbreak and significant public health issue [Lai et al, 2020].

The coronavirus belongs to a family of viruses that may cause various symptoms such as pneumonia, fever, breathing difficulty, and lung infection [WMHC, 2020]. COVID-19 is spread by human-to-human transmission through droplet, feco-oral, and direct contact and has an incubation period of 2-14 days [Backer et al, 2020]. Patients with COVID-19 present with pyrexia in $85 \%$ of cases during their illness course, but only $45 \%$ are febrile on early presentation [Guan et al, 2020]. Moreover, cough is seen in $67.7 \%$ of patients and sputum is produced in $33.4 \%$. Respiratory symptoms such as dyspnea, sore throat, and nasal congestion present in $18.6 \%, 13.9 \%$, and $4.8 \%$ of cases, respectively [Guan et al, 2020]. Constitutional symptoms such as muscle or bone aches, chills, and headache are seen in $14.8 \%, 11.4 \%$ and $13.6 \%$ of the cases, respectively [Guan et al, 2020]. Gastrointestinal (GI) symptoms such as nausea or vomiting and diarrhea are seen in $5 \%$ and $3.7 \%$ of the cases, respectively.

These viruses are common in animals worldwide, but very few cases have been known to affect humans. The World Health Organization (WHO) used the term 2019 novel coronavirus to refer to a coronavirus that affected the lower respiratory tract of patients with pneumonia in Wuhan, China on 29 December 2019 [Li et al, 2020, CDC, 2020, WHO, 2020]. The WHO announced that the official name of the 2019 novel coronavirus is coronavirus disease (COVID-19) [WHO, 2020]. And the current reference name for the virus is severe acute respiratory syndrome coronavirus 2 (SARS-CoV-2). It was reported that a cluster of patients with pneumonia of unknown cause was linked to a local Huanan South China Seafood
Market in Wuhan, Hubei Province, China in December 2019 [Zhu, et al, 2020].

On January 30, 2020, the World Health Organization (WHO) declared COVID-19 a public health emergency of international concern [WHO, 2020]. Astonishingly, during the first week of March, a devastating number of new cases were reported globally, and COVID-19 emerged as a pandemic. As of March 12, 2020, more than 125,000 confirmed cases across 118 countries and over 4600 deaths had been reported [WHO, 2020].

As of March 21, there have been 304,900 cases of which 94,793 have recovered and 13,001 have died [WHO, 2020]. Therefore, the worldwide case fatality rate (CFR) within this time period is $12 \%$. The current estimate of COVID-19 $\mathrm{R}_{\mathrm{o}}$ is 2-2.5 [WHO, 2020, Wu et al, 2020]. This can be interpreted as every case of COVID-19 can spread to two to three new people. Countries with the highest mortality rates are Italy, Spain, Iran, France, and the USA [CSSE, 2020]. Mortality rate increases in the 60 years and above cohort to $8.8 \%$ in comparison to $0.46 \%$ for patients less than 60 years old [WHO, 2020]. The mortality rate has a predilection for the male gender $(\mathrm{M}: \mathrm{F}=$ 1.7:1). Furthermore, the mortality rate also increases in patients with additional comorbidities, cardiovascular, diabetes and hypertension leading the cohort with mortality rates of $13.2 \%, 9.2 \%$, and $8.4 \%$, respectively [WHO, 2020].

In response to the outbreak, the Chinese Center for Disease Control and Prevention (China CDC) dispatched a rapid response team to accompany health authorities of Hubei province and Wuhan city to conduct epidemiological and etiological investigations. The WHO confirmed that the outbreak of the coronavirus epidemic was associated with the Huanan South China Seafood Marketplace, but no specific animal association was identified [WHO, 2020]. Within 1 month, this virus spread quickly throughout China during the Chinese New Year - a period when there is a high level of human mobility among Chinese people. Although it is still too early to predict susceptible populations, early patterns have shown a trend similar to Severe Acute Respiratory Syndrome (SARS) and Middle East respiratory syndrome (MERS) Coronaviruses. Susceptibility seems to be 
associated with age, biological sex, and other health conditions [Fehr et al, 2017].

Virus virulence is the disease causing capability of a virus which depends on various factors like those allow it to replicate and spread inside a host by modifying host defenses, and breaking host cells and damaging tissues. It is this infectious potential of a pathogen which determines the severity of symptoms [Burrell et al, 2017]. Coronaviruses are a group of highly diverse RNA virus in the Coronaviridae family that are divided in 4 genera: alpha, beta, gamma and delta that cause disease varying from mild to severe in human and animals [Hui and Zumla, 2019, Drosten et al, 2003, Azhar, EI et al, 2019 ].There are endemic human coronavirus as the alphacoronavirus 229E and NL63 and Betacoronaviruses OC43 and HKU1 that can cause influenza---like illness or pneumonia in humans [Hui and Zumla, 2019, Azhar, EI et al, 2019 ] . However, two zoonotic coronavirus have emerged causing severe disease in humans: severe acute Respiratory syndrome coronavirus (SARS---CoV) in 2002---2003 and Middle East respiratory syndrome coronavirus (MERS--CoV) [De et al, 2016, Hilgenfeld and Peiris, 2013]

In January 2020, the etiologic agent responsible for a cluster of severe pneumonia cases in Wuhan, China was identified as being a novel Betacoronavirus, but it is distinct from SARS--CoV and MERS---CoV [WHO, 2020, GISAID, 2020]. The complete genome sequence of this new agent has been released and different detection protocols have been developed but not fully validated yet. However, in light of the possible introduction of a suspected case related to 2019---nCoV in the America region, the Pan American Health Organization / World Health Organization (PAHO/WHO) recommends to Member States to ensure their timely identification, the shipping of samples to National and reference laboratories and the implementation of the molecular detection protocol for 2019---nCoV, according to the laboratory capacity.

There are different types of Corona viruses reported over the years. Tissue tropism varies with the type of corona virus i.e., alpha and beta corona viruses infect mammals; in contrast, gamma and delta corona viruses infect birds and fish, but some of them can also infect mammals [Chen et al, 2020]. The new 2019 novel Corona virus-2 or SARS-CoV-2 is identified as beta corona virus [Velavan and Meyer, 2020]. Virus virulence is basically due to its genes responsible for viral replication, genes which help to escape from host immune system, those which are involved in the transmissibility and genes coding toxic products in host cells. The current virus seems to be very contagious and has quickly spread globally [Cascella et al, 2020].

It directly correlates with the disease defense potential of an individual, specifically the innate and adaptive immune responses against pathogens [Owen et al, 2013]. Humans are generally and specifically immune to various kinds of viruses [Skountzou et al, 2010, Skountzou et al, 2014]. During the initial phase of Corona viral infection, the upper respiratory tract will be infected and the host immune power is the determining factor for disease progression [WHO, 2020]. A weakened immune defense may fail to compete with the viruses leading to lower respiratory tract infections, which on that stage may worse at a faster rate leading to lung fibrosis, shortness of breath and finally death. Genome studies have reported that a protein called nsp3 in the novel Corona Virus2 causing COVID 19 is meant for blocking host innate immune response and promoting cytokine expression [Lei et al, 2018, Cui et al, 2019]. The Immune-compromised persons are in a highly susceptible group as their host defense is very poor.

People with underlying health conditions like high Blood Pressure, diabetes, stroke, cardiac or kidney diseases, aged individuals, and people with weakened immune system face higher risks if COVID 19 like infections happens to them [Zhou et al, 2020, Raghupathi, 2019]. If people are challenged with COVID 19 after a recent viral infection, their defenses are already down and that could result in increasingly poor prognosis for them from this virus [Young et al, 2020]. This is mainly because of low levels of immune cells and high cytokine levels in body fluids. Cytokine release syndrome (CRS) is an acute systemic inflammatory syndrome characterized by fever and multiple organ dysfunctions. In some cases viral infections can illicit excessive immune reactions like 'cytokine storm' leading to tissue damage. This is mainly mediated by a chemical interleukin 6 (IL-6) produced by our immune cells. It was observed that other than viral infections, IL-6 level will also increases during cardiovascular diseases, infections, some forms of cancers, inflammatory 
and autoimmune disorders [Mehta et al, 2020]. COVID 19 often leads to CRS if other systemic health complications were previously present in a patient, a major cause of death. That is the reason why the people with underlying diseases are requested to stay safe otherwise they may not be able to cope with the excess IL- 6 levels upon infection which can lead to cytokine release syndrome (CRS) and even death [WHO, 2020].

Since the current pandemic can be spread by aerosol transmission from person to person, with direct or indirect contact [Riou and Althaus, 2020], intentional and thoughtful acts are the necessity of the time as Governments, communities, citizens, media, and other key influencers have an important role to play in preventing and stopping the pandemic which is highly influenced by host travel and other host behaviours leading to direct contact and spread of COVID 19 [ECDC, 2020]. The WHO guidelines restricting international travel from affected areas, clinical or home isolations and other advices and recommendations are having prime importance as they are meant to be strictly followed to reduce number of direct contacts and the general risk of transmission of this acute respiratory infection [WHO, 2020]. In addition to this, behavioral differences like restricted stay in indoors during winter can also have an effect on Corona viral spread [Wang, 2020].

Social distancing is one category of nonpharmaceutical countermeasures (NPCs) aimed to minimize physical contact between individuals and thereby to reduce the possibility for new infections [ECDC, 2020]. With the rapidly escalating COVID-19 pandemic, governments in all countries have been urged by World Health Organization to regard control of the disease as a 'top priority' [WHO, 2020]. Public health authorities and decision makers should raise the community consciousness regarding the mode(s) of transmission of the virus, need of community-level social distancing measures and other guidance aimed at minimizing the spread of COVID 19 with containment efforts like contact tracing. Social distancing measures, and their early, coordinated and comprehensive implementation and community consciousness are effective in slowing the spread of the virus [Wilder-Smith and Freedman, 2020, Kuper-Smith et al, 2020, Taderera, 2019].
Hand washing for at least 20 seconds after visiting public spaces. Soap or hand sanitizer with at least $60 \%$ of ethanol is recommended [IPAC, 2020]. It is also recommended to avoid touching the denoted facial T-zone (eyes, nose, and mouth) as this is the access point for virions into the upper respiratory tract [IPAC, 2020]. Avoiding contact with people who are already presenting with symptoms, as well as avoiding gathering or crowded places. Travel to outbreak areas must be prohibited. A healthy individual must maintain at least six feet distance from individuals presenting with symptoms [IPAC, 2020]. The sterilization of frequently handled surfaces is beneficial.

All healthcare workers managing COVID19 patients require full personal protective equipment (PPE) containing surgical masks, double gloves, full-sleeved procedural gowns, and eye shield [IPAC, 2020]. The N95 masks which prevent $95 \%$ of the droplets from entering the mask must be exclusively dawned prior to performing procedures associated with a higher risk for aerosol exposure such as tracheostomy, tracheal intubation, bronchoscopy, cardiopulmonary resuscitation (CPR), and noninvasive ventilation (NIV) [IPAC, 2020]. These procedures have the potential to aerosolize the virus. Containment of community transmissions is achieved by the closure of educational institutions, businesses, airspace, and sports events. High-risk individuals such as those older than 65 or having chronic comorbidities without any symptoms are also required to self- quarantine to decrease the likelihood of COVID-19 contraction [IPAC, 2020].

The higher case-fatality rate of COVID-19 reported in different countries suggests that it is more fatal in older patients [Onder et al, 2020]. Statistical reports states that the case fatality rate in Italy and China appear very similar for age groups 0-69 years, but rates are higher in Italy among individuals aged 70-80 years or older [WHO, 2020]. The reasons for this susceptibility can be either physical or social or both. Not only old ages compromise immunity and self defense making them more vulnerable to infectious diseases and acute respiratory 
distress syndrome but also more likely to have health conditions such as coronary, lung or kidney diseases, diabetes which can contribute to their low immunity levels. Stress can also cause people dying from heart attacks who have COVID-19 [Wu Z and McGowan, 2020]. Social isolation or mobility challenges are faced by the elderly in many societies, which may worsen the scene more than their weak immunity. In many countries, elderly are more likely to be in nursing or retirement home, or living with family in a more crowded situation where there's a greater risk of infection [Kane, 1980].

On 12th January 2020, the China CDC shared the genetic sequence of the SARSCoV-2. This enabled countries to develop primers against the SARS-CoV-2 genome and utilize reverse transcriptase polymerase chain reaction (RT-PCR) assays to make a diagnosis of COVID-19. Therefore, RT-PCR has become the gold standard for the diagnosis of COVID-19, but it is only $66-80 \%$ sensitive [Ai et al, 2020]. Essentially, this means that 20$34 \%$ of patients with COVID-19 out of 100 would test negative despite being infected. This variance in the sensitivity can be attributed to the patients being tested early in the disease course wherein the viral load is beneath detection level or due to lack of automation in sample preparation for RT-PCR. Furthermore, a single negative RT-PCR does not rule out COVID-19, hence a repeat RT-PCR must be performed. The concern rises regarding the timeframe of the repeat RT-PCR, the ideal window lies between 24 to 72 hours of the negative test.

Standard blood investigations revealed that most patients with COVID-19 have normal or decreased leucocytes, and lymphocytopenia. Furthermore, there is a systemic elevation of the pyrogenic cytokines such as IL-6, IL-10, and TNF- $\alpha$ [Guan et al, 2020, Wang et al, 2020, Chen et al, 2020, Shi et al, 2020, Huang et al, 2020]. In critical COVID-19 patients, neutrophilia, elevated D-dimer, increase in plasma blood urea nitrogen (BUN) and creatinine are also documented [Guan et al, 2020, Wang et al, 2020, Chen et al, 2020, Shi et al, 2020, Huang et al, 2020, Ai et al, 2020]. Patients admitted to the ICU will also have elevated plasma levels of the interleukins (IL-2, IL-7, and IL-10), and other chemokines such as Granulocyte Colony Stimulating Factor, $10 \mathrm{kD}$ Interferon-gamma-induced-protein10, Monocyte Chemo attractant Protein-1, and Macrophage Inflammatory Protein 1$\alpha$ [Huang et al, 2020].

The management of viral pneumonia is predominantly supportive amidst the absence of validated antiviral drugs. The most primary symptoms managed in COVID-19 are fever and non-productive cough, therefore the first-line antipyretic agent is Paracetamol and antitussive of choice is guaifenesin [Wang et al, 2020]. Supplementary oxygen at $5 \mathrm{~L} / \mathrm{min}$ must be administered for patients that require management of severe respiratory distress and the oxygen saturation ( $\mathrm{SaO} 2)$ target must be $\geq 92-95 \%$ in pregnant patients and $\geq 90 \%$ in all other patients [Chen et al, 2020].

In the majority of the cases, public health measures are vital for the management of the spread of COVID-19. If public health measures for containment are not adequate, then there will be a patient burden that supersedes the capacity of available ICU beds and mechanical ventilation, as seen in the crisis taking place in Italy. Therefore, the entire objective of the COVID-19 management rests on the premise of social distancing to suppress the rapid emergence influx of new cases in a short time frame. This epidemiological concept is referred to as the "flattening of the curve". The mainstay of public health must be to identify the infective cases, isolate these cases, attain contact tracing and isolate contacts that present with symptoms [Chen et al, 2020].

.On 28 January 2020, the Federal government of Nigeria assured citizens of the country of its readiness to strengthen surveillance at five international airports in the country to prevent the spread of coronavirus. The government announced the airports as Enugu, Lagos, Rivers, Kano and the FCT. [CoV, 2020]. The Nigeria Centre for Disease Control also announced same day that they had already set up coronavirus group and was ready to activate its incident system if any case emerged in Nigeria [Odunsi, 2020]. 
On 31 January 2020, following the developments of COVID-19 pandemic in mainland China and other countries worldwide, the federal government of Nigeria set up a Coronavirus Preparedness group to mitigate the impact of the virus if it eventually spreads to the country. [Ifijeh, 2020]. On the same day, the World Health Organization listed Nigeria among other 13 African countries identified as high-risk for the spread of the virus. [Ezigbo, 2020].

On 27 February, Nigeria confirmed its first case in Lagos State, an Italian citizen who works in Nigeria had returned on 25 February from Milan, Italy through the Murtala Muhammad International Airport, fell ill on 26 February and was transferred to Lagos State bio-security facilities for isolation and testing. [NCDC, 2020, Ugbodaga, 2020].

The Nigeria Centre for Disease Control (NCDC) has continued to lead the public health response to the COVID-19 outbreak in Nigeria. Till date, the disease has spread to 34 states and the Federal Capital Territory (FCT). As at 10th of May 2020, there are 4399 confirmed cases and 143 deaths recorded. Following the confirmation of the index case of COVID-19 in Nigeria on the 27th of February, a COVID-19 national Emergency Operations Centre (EOC) was immediately activated on the 28th of February. Since then, the NCDC has continued to implement measures to control the spread of this disease including the deployment of Rapid Response Teams (RRTs) to support response activities in affected states. Given the novelty of the virus and level of response initiated, the NCDC convened a review meeting on the 9th of May 2020 to discuss the first 72 days of response (NCDC, 2020).

Recent reports of hundreds more deaths than usual across communities in Nigeria's Kano State have raised fears that a major Covid-19 outbreak is underway. Official data from Kano State Ministry of Health reports 219 confirmed Covid-19 cases and five deaths as of April 30, but residents fear that the outbreak may have caused far more devastation. Authorities should act quickly to ensure accurate public health information is available and accessible to all. The Kano State Ministry of Health reports 342 confirmed Covid-19 cases and 8 deaths as of May 3. Like most parts of Nigeria, healthcare infrastructure in Kano is poor and if not quickly contained, an outbreak among the estimated population of 13.4 million may result in significant deaths. State authorities have acknowledged the unusually high number of deaths, and while they initially denied they were related to coronavirus they are now conducting "verbal" autopsies. Considering Kano's low literacy rate, the authorities should ensure that public health information is accessible to all and available in relevant languages. They should also act swiftly to identify, isolate, and treat Covid-19 cases as well as trace contacts, in order to curb the virus' spread. At this time of crisis, the government should work with trusted community-based groups, religious leaders, and community radio stations to protect citizens by equipping them with the right information (KMOH, 2020). Poor knowledge and perceptions towards COVID-19 contributed to the prolonged transmission of diseases in the community. Therefore the aim of this study was to assess knowledge and perceptions towards COVID-19 among GyadiGyadi communities in Kano, Nigeria.

\section{Methodology}

\subsection{Study Area and Study Design}

The study was conducted in Gyadi-Gyadi which is one of the towns found in Tarauni local government Kano state. The estimated population of the Gyadi-Gyadi communities was 664147. A community-based cross- sectional study was conducted using intervieweradministered questionnaire from April, 2020 to May, 2020.

\subsection{Sample Size Determination}

In this study, manual calculation of the sample size using Morgan and Krejcie (1970) formula was used for sample size determination as stated below:

\section{$S=X^{2} N P(1-P) \div d^{2}(N-1)+X^{2} P(1-P)$ \\ Where:}

$\mathbf{S}=$ Required sample size

$\mathbf{X}^{\mathbf{2}}=$ The table value of the chi-square at desired confidence (3.841)

$\mathbf{N}=$ Study Population size (1367)

$\mathbf{P}=$ Population proportion assumed to be $\mathbf{0 . 5 0}$ since this would provide maximum sample size $\mathbf{d}^{2}=$ Degree of accuracy of the result expressed as proportion $\mathbf{0 . 0 5 0}$

$3.841 \times 1367 \times 0.5 \times 0.5$ $0.0025 \times 1366+3.841 \times 0.5 \times 0.5$

$\underline{1312.66175}=300$ 


\subsection{5}

Hence 300 respondents

\subsection{Inclusion And Exclusion Criteria}

Resident individuals aged 18 years and above and willing to participate were included in the study. Individuals who stayed as guests in the selected households, those who were $<18$ years of age and who had chronic illnesses were excluded from the study.

\subsection{Data Collection}

Data was collected from eligible and willing participants using a pre-tested, structured questionnaire. Socio-demographic information including age, gender, occupation, education and socio-economic status were collected. The knowledge of the participants on symptoms suggestive of COVID-19 causes of COVID-19, treatment and preventive measures, regarding COVID-19 was also collected.

\subsection{Data Analysis}

Data were analyzed using Statistical Package for Social Science (SPSS) software version 16.0 at that time with the help of the Statistician. The descriptive statistical method was used to analyze frequencies and percentages.

\subsection{Ethical Considerations}

This study was conducted only after obtaining approval from Gyadi-Gyadi District Head.

\section{RESUltS}

A total of 300 respondents were interviewed, giving $100 \%$ response rate. The majority, 165 (55\%) of the respondents were males. Among all, $115(38.3 \%)$ of respondents were $31-35$ years of age. Of the study subjects, 195 (65\%), were married. The socio-economic characteristics of the study showed that, among all respondents, $180(60 \%)$ of respondents attended formal education, among this 145(48.3\%) of respondents were secondary school completed, $35(11.7 \%)$ of respondents were primary school completed, while $120(40 \%)$ of respondents reported that they were took informal education (were illiterate and only read and write). Similarly, results of occupational status of respondents indicated, $150 \quad(50 \%)$ of respondents were civil servants, $70(23.3 \%)$ were company employee, $45(15 \%)$ were Merchants and $35(11.7 \%)$ were House wives (Table 1).

\subsection{Knowledge of The Respondents towards COVID-19}

From a total of three hundred (300) respondents' majority 185 (61.7\%) know COVID-19, and also 178 (59.3\%) heard COVID-19. Concerning sources of information about COVID-19, 95 (31.7\%), 118 (39.3\%), 87 (29\%) got information from family and friends, Social media and News media. Regarding the origin of COVID-19 98 (32.7\%) of the respondents answered COVID19 originates from bats. Concerning transmission majority 175 (58.3\%) of the respondents have answered COVID-19 is transmitted through air, contact, fecal-oral routes. Regarding sign and symptom most of $162(54 \%)$ of the respondents have answered Headache, fever, cough, sore throat, and flu are symptoms of COVID-19. Regarding the incubation period $89(29.7 \%)$ of the respondents answered 14 days as the incubation period of COVID-19. $182(60.7 \%)$ of the respondents answered COVID-19 leads to pneumonia, respiratory failure, and death. However, majority 194 (64.7) of the respondents answered Supportive care is the current treatment for COVID-19. Concerning the way of prevention majority 175 (58.3\%) answered Wearing of face mask, Hand hygiene, covering nose and mouth while coughing, and avoiding sick contacts can help in the prevention of COVID-19 transmission (Table 2).

Table 1. Socio demographic characteristics of respondents $(n=300)$

\begin{tabular}{|l|l|l|}
\hline Characteristics & Frequencies & $\begin{array}{c}\text { Percentages } \\
\text { \% }\end{array}$ \\
\hline Gender & & \\
\hline Males & 165 & 55 \\
\hline Females & 135 & 45 \\
\hline Ages & & \\
\hline $20-25$ & 60 & 20 \\
\hline $26-30$ & 65 & 21.7 \\
\hline $31-35$ & 115 & 38.3 \\
\hline $36+$ & 60 & 20 \\
\hline Marital status & & \\
\hline Married & 195 & 65 \\
\hline Single & 85 & 28.3 \\
\hline Divorced & 8 & 2.7 \\
\hline Widowed & 12 & 4 \\
\hline Education & & \\
\hline $\begin{array}{l}\text { Secondary } \\
\text { above }\end{array}$ & 145 & 48.3 \\
\hline Primary & 35 & 11.7 \\
\hline Can read and write & 45 & 15 \\
\hline Illiterate & 75 & 25 \\
\hline Occupation & & \\
\hline Civil servant & 150 & 50 \\
\hline Company Employee & 70 & 23.3 \\
\hline Merchants & 45 & 15 \\
\hline House Wife & 35 & 11.7 \\
\hline & & \\
\hline
\end{tabular}


Epidemiological Assessment of Knowledge and Perceptions towards Corona Virus Disease-19 Among Gyadi-Gyadi Communities in Kano, Nigeria

Table 2. Knowledge of the respondents towards COVID-19 $(n=300)$

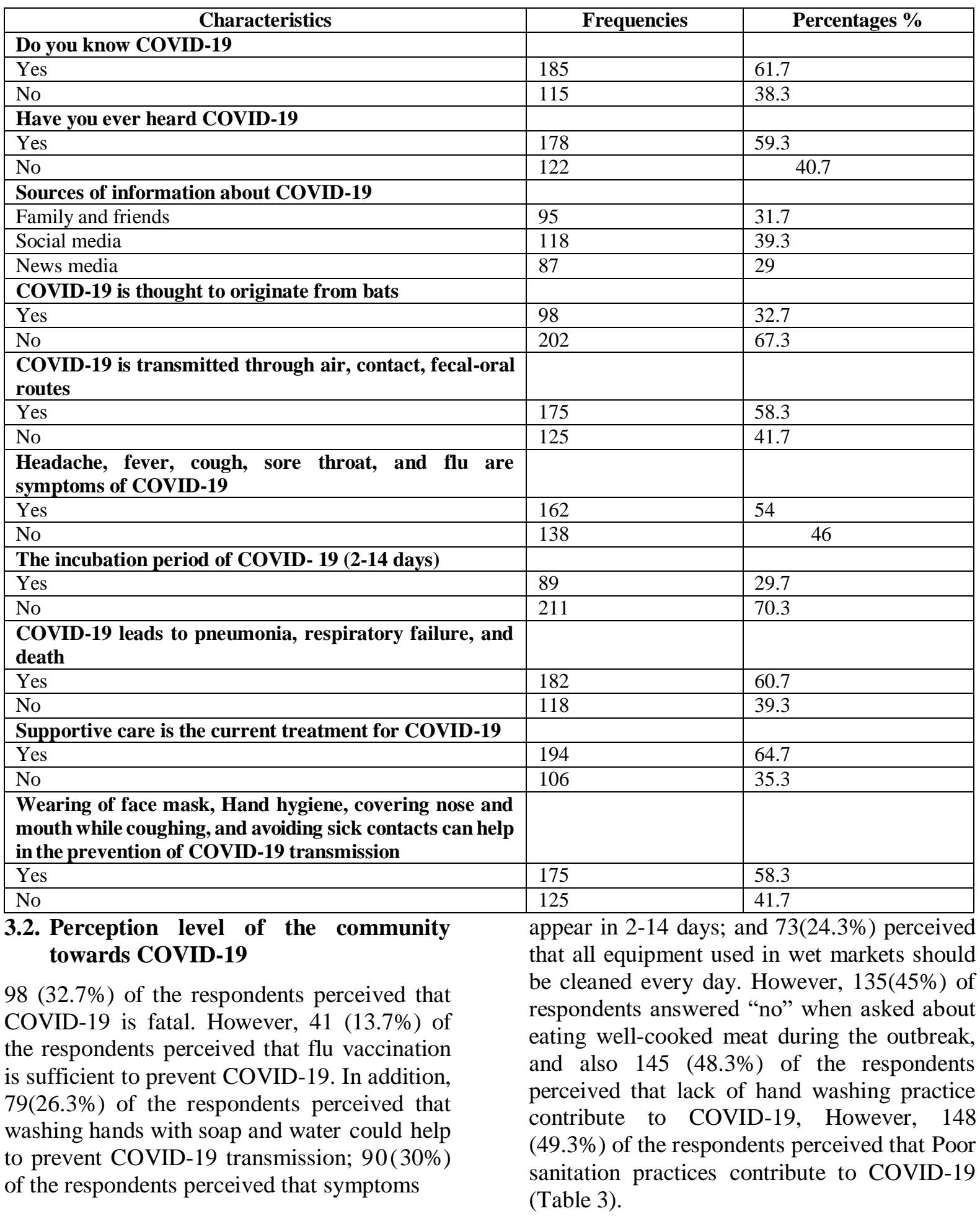

Table 3. Perceptions of the respondents towards COVID-19 $(n=300)$

\begin{tabular}{|l|c|c|}
\hline \multicolumn{1}{|c|}{ Characteristics } & Frequencies & Percentages \% \\
\hline COVID-19 is fatal & & \\
\hline Yes & 98 & 32.7 \\
\hline No & 202 & 67.3 \\
\hline $\begin{array}{l}\text { Washing hands with soap and water can help in the prevention of } \\
\text { COVID-19 transmission }\end{array}$ & & \\
\hline Yes & 79 & 26.3 \\
\hline No & 221 & 73.7 \\
\hline Flu vaccination is sufficient for preventing COVID-19 & & \\
\hline
\end{tabular}


Epidemiological Assessment of Knowledge and Perceptions towards Corona Virus Disease-19 Among Gyadi-Gyadi Communities in Kano, Nigeria

\begin{tabular}{|l|c|c|}
\hline Yes & 41 & 13.7 \\
\hline No & 259 & 86.3 \\
\hline COVID-19 symptoms appear in 2-14 days & 90 & 30 \\
\hline Yes & 210 & 70 \\
\hline No & & \\
\hline $\begin{array}{l}\text { Disinfect equipment and working area in wet markets at least once } \\
\text { a day }\end{array}$ & 73 & 24.3 \\
\hline Yes & 227 & 75.7 \\
\hline No & & \\
\hline $\begin{array}{l}\text { During the outbreak, eating well-cooked and safely handled meat } \\
\text { issafe }\end{array}$ & 135 & 45 \\
\hline Yes & 165 & 55 \\
\hline No & & \\
\hline Lack of hand washing practices contributes to COVID-19 & 145 & 48.3 \\
\hline Yes & 155 & 51.7 \\
\hline No & & \\
\hline Poor sanitation practices contribute to COVID-19 & 148 & 49.3 \\
\hline Yes & 152 & 50.7 \\
\hline No & 2020 \\
\hline
\end{tabular}

\section{DISCUSSION}

At present, COVID-19 is a global topic of discussion in the media and among the public. With the currently mounting COVID-19 transmission raising tensions for everyone, including for health officials and health systems, an important question arises regarding how we manage information to help frontline Health Care Workers (HCWs) in times of public health crisis. For this reason, we investigated communities' knowledge and perceptions of the prevention and control of COVID-19 at the pandemic level

Knowledge and perceptions of COVID-19 varied across different categories of respondents. Our study revealed that respondents have low knowledge about COVID19 but showed negative perceptions of COVID19 transmission prevention. We also found that $95(31.7 \%)$ of respondents used family and friends as a primary source of information about COVID-19. This indicates obtaining information from authentic sources is pivotal for disseminating unbiased and reliable data about the emerging COVID-19 infection and is essential for respondents' preparedness and response. However, a finding of considerable concern is that $118(39.3 \%)$ of respondents used social media as a source of information. Currently, there is a vast diversity of information available through the internet, including unverified malicious information that can spread quickly and misguide respondents. In particular, health authorities and scientists have warned that widespread misinformation about COVID-19 is a serious concern causing xenophobia worldwide [Lai et al, 2020, Thomas,
2020, Shimizu, 2020, Mejova and Kalimeri, 2020]. In this regard, respondents should carefully evaluate COVID-19-related information and should use scientific and authentic content as information sources. The findings of this study suggest a significant gap between the amount of information available on COVID-19 and the depth of knowledge among respondents, particularly about the mode of transmission and the incubation period of COVID-19.

\section{CONCLUSION}

The study revealed that, the respondents has low knowledge towards COVID-19. However, majority have poor perceptions towards COVID-19. Therefore, according to this research education has its own contribution for perceptions. In general, according to the study the perceptions level of the community is poor. Since knowledge and perceptions are the key factor for the control and prevention of COVID19 , strengthen the awareness of the community towards COVID-19 is mandatory. As the global threat of COVID-19 continues to emerge, greater efforts through educational campaigns and Supportive supervision for health extension workers in order to strengthen effective health education to the community on the causes, sign and symptoms of the diseases and possible preventives measures are urgently needed.

\section{ACKNOWLEDGMENTS}

I am grateful to thank the study participants and acknowledge the team of research assistants.

\section{REFERENCES}

[1] Ai T, Yang Z, Hou H, et al. (2020). Correlation of chest $\mathrm{CT}$ and RT-PCR 
testing in Coronavirus Disease 2019 (COVID-19) in China: a report of 1014 cases. Radiology. (2020), [Published online ahead of print]:10.1148/radiol.2020200642

[2] Azhar, EI et al. (2019).The Middle East Respiratory Syndrome (MERS). [book auth.] Boucher HW, Zumla A And DSC Hui. Emerging and Re---emerging Infectious Dseases --- Clinics Rebiew Articles. Philadelphia : Elsevier, (2019), pp. 891---905

[3] Backer J, Klinkenberg D, Wallinga J. (2020). Incubation period of 2019 novel coronavirus (2019-nCoV) infections among travellers from Wuhan, China, 20-28 January (2020). Euro Surveill (2020); 25(5). [doi: 10.2807/15607917.es.2020.25.5.2000062]

[4] Bhagavathula AS, Shehab A. (2020). The Story of Mysterious Pneumonia and the Response to Deadly Novel Coronavirus (2019-nCoV): So Far!. NEMJ (2020) Feb 21; 1(1):7-10. [doi: 10.2174/0250688202001010007]

[5] Burrell CJ, Howard CR, Murphy FA, et al. (2017). Chapter 29 - bunyaviruses. Fenner White Med Virol. (2017): 407- 424.

[6] Cascella M, Rajnik M, Cuomo A, et al. (2020). Features, evaluation and treatment coronavirus (COVID-19). StatPearls Publishing; (2020) [cited 2020 March 30]. Available from: https://www.ncbi.nlm.nih.gov/books/NBK5547 $76 /$

[7] Centers for Disease Control and Prevention (2019.Update and interim guidelines on outbreak of 2019 Novel coronavirus (2019nCoV) URL: https://emergency.cdc.gov/han/ han00427.asp [accessed 2020-02-12]

[8] Chen N, Zhou M, Dong X, et al. ( 20020$)$. Epidemiological and clinical characteristics of 99 cases of 2019 novel coronavirus pneumonia in Wuhan, China: a descriptive study. Lancet. (2020), 395:507513. 10.1016/S0140-6736(20)30211-7

[9] Chen H, Guo J, Wang C, et al. (2020) Clinical characteristics and intrauterine vertical transmission potential of COVID19 infection in nine pregnant women: a retrospective review of medical records. Lancet. (2020), 395:809-815. 10.1016/ S01 40-6736(20)30360-3

[10] Centers for Disease Control China. (2020). The epidemiological characteristics of an outbreak of 2019 Novel Coronavirus Disease (COVID19) - China; (2020) [cited 2020 March 30]. Available from: http://www.ourphn.org.au/wpcontent/uploads/ 20200225-Article-COVID-19. pdf

[11] Chen, Y., Liu, Q., Guo, D. (2020). Emerging corona viruses: genome structure, replication, and pathogenesis. J Med Virol. (2020). DOI:10.1002/jmv.25681
[12] Cui J, Li F, Shi ZL. (2019). Origin and evolution of pathogenic corona viruses. Nat Rev Microbial. (2019) ;17(3):181-192.

[13] Center for Systems Science and Engineering (2020).Coronavirus COVID-19 global cases by the at Johns Hopkins University (JHU). Accessed: March 22, (2020): https://coronavirus.jhu.edu/map.html.

[14] Coronavirus (2020). Nigeria 'strengthens' surveillance at five international airports". Premium Times. 29 January (2020). Retrieved 10 March (2020).

[15] De Wit, E, et al. (2016). SARS and MERS: recent insights into emerging coronaviruses. Nature Reviews Microbiology. 2016, Vol. 14, pp. 523---524.

[16] Drosten C, et al. (2003). Severe acute respiratory syndrome: identification of the etiological agent. Trends Mol Med. (2003), Vol. 9, pp. 325---7.

[17] European Centre for Disease Prevention and Control (2020). COVID- 19 [cited 2020 March 30]. Available from: https://www.ecdc.europa. eu/en/ novel-coronavirus-china

[18] European Centre for Disease Prevention and Control (2020) technical report. Guidelines for the use of non pharmaceutical measures to delay and mitigate the impact of 2019-nCoV; [cited 2020 March 30]. Available from: https://www.ecdc.europa.eu/sites/ default/ files/ documents/novel- coronavirus-guidelines- nonpharmaceuticalmeasures_0.pdf.

[19] Ezigbo, Onyebuchi; Ifijeh, Martins (1 February 2020). "Coronavirus Spread: WHO Lists Nigeria among High Risk Countries". This Day Newspaper. Retrieved 10 March (2020).

[20] Fehr AR, Channappanavar R, Perlman S. (2017). Middle East respiratory syndrome: emergence of a pathogenic human coronavirus. Annu Rev Med. (2017) ;68: 387-99.

[21] Global Initiative on Sharing All Influenza Data (2020). Newly discovered betacoronavirus, Wuhan 2019---2020. GISAID EpiFlu --- Global Initiative on Sharing All Influenza Data. [Online] January (2020). https://platform. gisaid.org/epi3/frontend\#414223.

[22] Guan W-j, Ni Z-y, Hu Y, et al. (2020). Clinical characteristics of coronavirus disease 2019 in China . N Engl J Med. (2020), [Published online ahead of print]:10.1056/NEJMoa2002032

[23] Hilgenfeld R, and Peiris M, (2013). From SARS to MERS: 10 years of research on highly pathogenic human corona viruses. Antiviral Res. (2013), Vol. 100, pp. 286---95.

[24] Huang C, Wang Y, Li X, et al. (2020) Clinical features of patients infected with 2019 novel coronavirus in Wuhan, China. 
Lancet. (2020), 395:497-506. 10.1016/S0140-6736(20)30183-5

[25] Hui, DSC and Zumla, A. (2019). Severe Acute Respiratory Syndrome --- Historical, Epidemiologic; and Clinical Features. [book auth.] HW Boucher, A Zumla and DSC Hui. Emerging and Re---emerging Infectious Diseases --- Clinics Revew Articles. Philadelphia: Elsevier, (2019), pp. 869---889.

[26] Ifijeh, Martins (31 January 2020). "FG Sets up Coronavirus Preparedness Group". This Day Newspaper. Retrieved 10 March 2020

[27] Infection Prevention and Control (2020). Updated recommendations for use of personal protective equipment for care of individuals with suspect or confirmed COVID-19. (2020). Accessed: March 23, (2020) : https:// www.publichealthontario .ca/-/media/documents/ncov/updated-ipacmeasures-covid- 19.pdf?la=en.

[28] Kane RL, Kane RA. (1980). Long-term care: can our society meet the needs of its elderly? Annu Rev Public Health. (1980); 1(1):227-253.

[29] Kano State Ministry of Health (2020). Kano suspends official gatherings directs closure of event centres. The Nation Newspaper. 23 March (2020). Retrieved 23 March (2020).

[30] Kuper-Smith BJ, Doppelhofer LM, Oganian Y, et al. (2020). Optimistic beliefs about the personal impact of COVID-19; (2020). DOI:10.31234/osf.io/epcyb

[31] Lai C, Shih T, Ko W, Tang H, Hsueh P. (2020). Severe acute respiratory syndrome coronavirus 2 (SARS-CoV-2) and coronavirus disease-2019 (COVID-19): The epidemic and the challenges. Int J Antimicrob Agents (2020) Mar;55(3):105924 [FREE Full text] [doi: 10.1016/j.ijantimicag.2020.105924] [Medline: 32081636]

[32] Li Q, Guan X, Wu P, Wang X, Zhou L, Tong Y, et al. (2020). Early Transmission Dynamics in Wuhan, China, of Novel Coronavirus-Infected Pneumonia. N Engl J Med (2020) Mar 26;382(13):1199-1207 [FREE Full text] [doi: 10.1056/NEJMoa2001316] [Medline:3199 585 7]

[33] Lei J, Kusov Y, Hilgenfeld R. (2018). Nsp3 of corona viruses: structures and functions of a large multi-domain protein. Antiviral Res. (2018); 149:58-74.

[34] Mehta P, McAuley DF, Brown M, et al. (2020). COVID-19: consider cytokine storm syndromes and immunosuppression. Lancet. (2020). DOI:10.1016/S0140-6736(20)30628-0moe .gov.ae/En/MediaCenter/News/pages/SpringVa cation.aspx [accessed 2020-02-28]

[35] Mejova Y, Kalimeri K. (2020). Advertisers Jump on Coronavirus Bandwagon: Politics, News, and Business (preprint;ar
Xiv:2003.00923). ar Xiv.org 2020 [FREE Full text]

[36] Morgan DW and Krejcie, RV. (1970). Determining Sample size for research activities of Minnesota: USA.

[37] Nigeria Centre for Disease Control (2020). Ncdc.gov.ng. Archived from the original on 2 March (2020). Retrieved 8 March (2020).

[38] Odunsi, Wale (28 January 2020). "Coronavirus: Nigeria announces preventive measures, releases numbers". Daily Post Nigeria. Retrieved 10 March (2020).

[39] Onder G, Rezza G, Brusaferro S. (2020). Casefatality rate and characteristics of patients dying in relation to COVID- 19 in Italy. JAMA. (2020). DOI:10.1001/jama.2020.4683

[40] Owen JA, Punt J, Stranford SA, et al. Kuby immunology. 7th ed. New York: WH Freeman; (2013).

[41] Raghupathi V. (2019). An empirical investigation of chronic diseases: a visualization approach to Medicare in the United States. Int J Healthc Manag. (2019) ;12(4):327-339.

[42] Riou J, Althaus CL. (2020). Pattern of early human-to-human transmission of Wuhan 2019 novel coronavirus (2019- nCoV), December (2019) to January (2020). Eurosurveillance. (2020); 25(4). DOI:10.2807/15607917.ES.2020.25.4.2000058

[43] Shi H, Han X, Jiang N, et al. (2020). Radiological findings from 81 patients with COVID-19 pneumonia in Wuhan, China: a descriptive study. Lancet Infect Dis. (2020), 20:425-434.10.1016/S1473-3099(20)300 86-4

[44] Shimizu K. (2020) 2019-nCoV, fake news, and racism. The Lancet 2020 Feb; 395(10225):685686. [doi: 10.1016/s0140-6736(20)30357-3]

[45] Skountzou I, Koutsonanos DG, Kim JH, et al. (2010). Immunity to pre-1950 H1N1 influenza viruses confer across-protection against the pandemic swine-origin (2009) A (H1N1) influenza virus. J Immunol. (2010); 185 (3):1642-1649.

[46] Skountzou I, Satyabhama L, Stavropoulou A, et al. (2014). Influenza virus-specific neutralizing IgM antibodies persist for a lifetime. Clin Vaccine Immunol. (2014); 21 (11):1481-1489.

[47] Taderera BH. (2019). Community health volunteers and their role in health system strengthening in peri-urban areas: a qualitative study of Epworth, Zimbabwe. Int J Healthc Manag. (2019): 1-9. DOI:10.1080/20479700. 2019.1647379.

[48] Thomas Z. (2020) BBC News. (2020 Feb 13). Misinformation on coronavirus causing 
'infodemic' URL: https://www.bbc.com/news/ technology-51497800 [accessed 2020-03-09]

[49] Ugbodaga, Kazeem (28 February 2020). "Breaking: Deadly Coronavirus confirmed in Lagos Nigeria at last". P.M. News. Retrieved 10 March (2020).

[50] Velavan TP, Meyer CG. (2020). The COVID19 epidemic. Trop Med Int Health. (2020); 25(3):278-280. DOI: 10. 1111/tmi.13383

[51] Wang D, Hu B, Hu C, et al. (2020). Clinical characteristics of 138 hospitalized patients with 2019 novel coronavirus-infected pneumonia in Wuhan, China. JAMA. (2020), 323:1061-1069. 10.1001/jama.2020.1585

[52] Wang Y, Wang Y, Chen Y, et al. Unique epidemiological and clinical features of the emerging 2019 novel coronavirus pneumonia (COVID-19) implicate special control measures. J Med Virol. (2020). DOI:10.1002/jmv. 25748

[53] Wilder-Smith A, Freedman DO. (2020). Isolation, quarantine, social distancing and community containment: pivotal role for oldstyle public health measures in the novel coronavirus (2019-nCoV) outbreak. J Travel Med. (2020);27:2. DOI:10.1093/jtm/taaa020.

[54] World Health Organization (2020). Infection prevention and control during health care when novel coronavirus ( $\mathrm{nCoV})$ infection is suspected: interim guidance, January (2020) URL: https://tinyurl.com/r7w9key [accessed 2020-02-12]

[55] World Health Organization (2020). Responding to COVID-19: Real-time training for the coronavirus disease outbreak URL: https://openwho.org/channels/covid-19 [acces sed 2020-02-01]

[56] World Health Organization (2020). Laboratory testing of human suspected cases of novel coronavirus (nCoV) infection --- Interim guidance. WHO/2019---nCoV/laboratory/ 2020.1. [Online] January 17, (2020).https: // www.who.int/health---topics/coronavirus/ laboratory---diagnostics---for---novel-coronavirus.

[57] World Health Organization (2020). Emerging respiratory viruses, including COVID-19: methods for detection, prevention, response, and control URL: https://openwho.org/ courses/ introduction-to-ncov [accessed 2020-02-01]

[58] World Health Organization (2020). Coronavirus disease (COVID-19) outbreak [cited 2020 March 30]. Available from: https:// www.who.int/emergencies/diseases/novelcoronavirus- 2019

[59] Wilder-Smith A, Freedman DO. Isolation, quarantine, social distancing and community containment: pivotal role for old-style public health measures in the novel coronavirus (2019-nCoV) outbreak. J Travel Med. (2020); 27:2. DOI:10.1093/jtm/taaa020.

[60] Wu JT, Leung K, Bushman M, et al. (2020). Estimating clinical severity of COVID-19 from the transmission dynamics in Wuhan, China. Nat Med. (2020), [Published online ahead of print]:10.1038/s41591-020-08227

[61] Wu Z, McGoogan JM. (2020). Characteristics of and important lessons from the coronavirus disease 2019 (COVID-19) outbreak in China: summary of a report of 72314 cases from the Chinese Center for Disease Control and Prevention. JAMA. (2020). DOI:10.1001/ jama.2020.2648

[62] Yin Y, Wunderink RG. (2018). MERS, SARS and other corona viruses as causes of pneumonia. Respirology (2018) Feb 20;23(2):130-137 [FREE Full text] [doi: 10.1111/resp.13196] [Medline: 29052924]

[63] Young BE, Ong SWX, Kalimuddin S, et al. (2020). Epidemiologic features and clinical course of patients infected with SARS-CoV-2 in Singapore. JAMA. (2020).DOI:10.1001/ja ma.2020.3204

[64] Zhai Y, Du X. (2020). Mental health care for international Chinese students affected by the COVID-19 outbreak. Lancet Psychiatry. (2020); 7(4):e22. DOI:10.1016/S2215- 0366 (20)30089-4

[65] Zhou F, Yu T, Du R, et al. (2020). Clinical course and risk factors for mortality of adult in patients with COVID-19 in Wuhan, China: a retrospective cohort study. Lancet. (2020). DOI:10.1016/S0140-6736(20)30566-3

[66] Zhu N, Zhang D, Wang W, Li X, Yang B, Song J, et al. (2020). A Novel Coronavirus from Patients with Pneumonia in China,2019. N Engl J Med (2020) Feb 20; 382(8):727-733. [doi: 10.1056/nejmoa2001017

Citation: Ahmad Salisu Aliyu, Ahmed Habibu Badawi, Hussaini Mohammed, Nuru Yakubu Umar, Samira Shehu. Epidemiological Assessment of Knowledge and Perceptions towards Corona Virus Disease-19 among Gyadi-Gyadi Communities in Kano, Nigeria.ARC Journal of Public Health and Community Medicine. 2020; 5(2):1-12. DOI: dx.doi. org /10.20431/ 2456-0596.0502001.

Copyright: (C) 2020 Authors. This is an open-access article distributed under the terms of the Creative Commons Attribution License, which permits unrestricted use, distribution, and reproduction in any medium, provided the original author and source are credited. 